Old Dominion University

ODU Digital Commons

2018

Supporting Mathematics Coaches' Learning of Probability through Professional Development Tasks

Mary C. Enderson

Melva R. Grant

Yating Liu

Follow this and additional works at: https://digitalcommons.odu.edu/teachinglearning_fac_pubs

Part of the Science and Mathematics Education Commons, and the Teacher Education and Professional Development Commons 


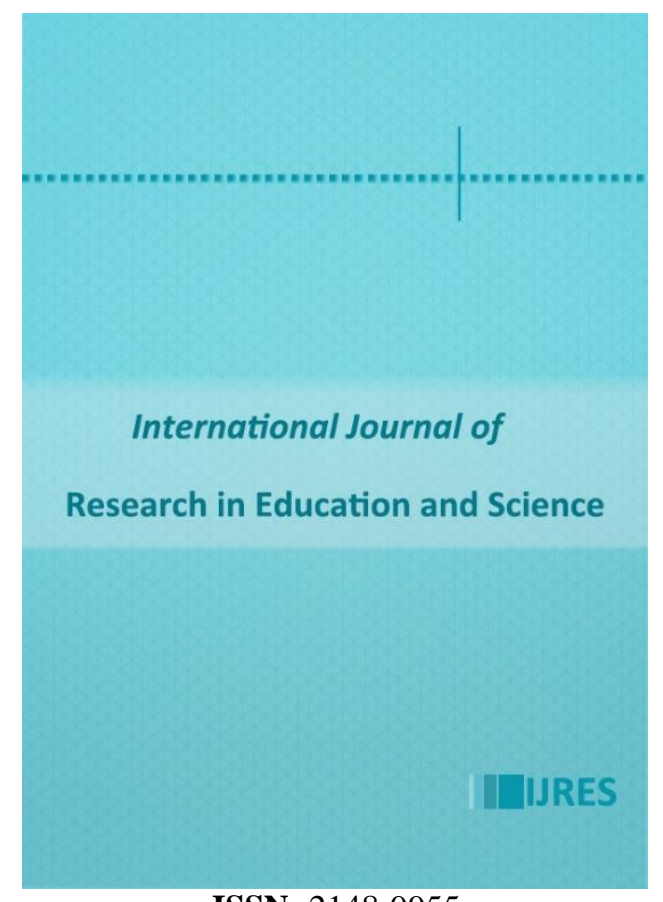

\section{Intemational Jounal of Research in Education and Science (IJRES)}

www.ijres.net

$\begin{array}{lll}\text { Supporting } & \text { Mathematics } & \text { Coaches' } \\ \text { Learning of } & \text { Probability } & \text { through } \\ \text { Professional Development Tasks } & \end{array}$

Mary C. Enderson ${ }^{1}$, Melva R. Grant ${ }^{1}$, Yating Liu ${ }^{2}$

${ }^{1}$ Old Dominion University

${ }^{2}$ Art of Problem Solving

ISSN: $2148-9955$

To cite this article:

Enderson, M.C., Grant, M.R., \& Liu, Y. (2018). Supporting mathematics coaches' learning of probability through professional development tasks. International Journal of Research in Education and Science (IJRES), 4(2), 613-632. DOI:10.21890/ijres.428976

This article may be used for research, teaching, and private study purposes.

Any substantial or systematic reproduction, redistribution, reselling, loan, sub-licensing, systematic supply, or distribution in any form to anyone is expressly forbidden.

Authors alone are responsible for the contents of their articles. The journal owns the copyright of the articles.

The publisher shall not be liable for any loss, actions, claims, proceedings, demand, or costs or damages whatsoever or howsoever caused arising directly or indirectly in connection with or arising out of the use of the research material. 


\title{
Supporting Mathematics Coaches' Learning of Probability through Professional Development Tasks
}

\author{
Mary C. Enderson, Melva R. Grant, Yating Liu
}

\begin{tabular}{|c|c|}
\hline Article Info & Abstract \\
\hline Article History & $\begin{array}{l}\text { This study was conducted to propose a framework of professional } \\
\text { development tasks (PDTs) that may be used to enhance mathematics coaches' }\end{array}$ \\
\hline $\begin{array}{l}\text { Received: } \\
26 \text { September } 2017\end{array}$ & $\begin{array}{l}\text { content knowledge and understanding of student work, as well as to help them } \\
\text { conceptualize their role in facilitating a professional learning community in }\end{array}$ \\
\hline $\begin{array}{l}\text { Accepted: } \\
14 \text { May } 2018\end{array}$ & $\begin{array}{l}\text { school. In this qualitative design experiment, researchers developed and } \\
\text { implemented a set of PDTs to use with elementary and middle school } \\
\text { mathematics coaches. The PDTs, with a focus on K-8 probability topics, }\end{array}$ \\
\hline Keywords & $\begin{array}{l}\text { oaches to conduct mathematics problem solving, student work } \\
\text { d create a community to reflect individually and collaboratively on }\end{array}$ \\
\hline Mathemat & es. Qualitative data from the coaches' self-reflective writing \\
\hline & cated a positive impact of PDTs and work samples illustrated their \\
\hline $\mathrm{Pr}_{1}$ & periences in the learning process. The structure of PDTs used in the study \\
\hline & Inthesized into a framework that could be utilized by coach or teacher \\
\hline & educators as a generic tool for professional development. \\
\hline
\end{tabular}

\section{Introduction}

Coaching is a major industry in the United States where research on mathematics specialists or coaches and their training has begun to gain greater attention (Campbell \& Malkus, 2010; 2011; Whitenack \& Ellington, 2009; 2013). There is a consensus that effective mathematics coaches need strong content and pedagogical knowledge to influence their mathematical practices. This study was designed to contribute to the emerging literature of mathematics coaches for improving mathematics teaching and learning. In particular, researchers designed and implemented a set of professional development tasks for strengthening coaches' understanding about probability concepts and reflecting on their own and Grades 3-8 students' thinking about the concepts. The impact of problem-based professional development tasks on mathematics coaches, more specifically on their perceptions of the capacities needed for effective coaching, was of interest. Tasks were integrated into a graduate-level course as part of a university PK-8 Mathematics Specialists Program.

Currently, coaching has emerged as a viable substitute to traditional professional development for teachers (Kraft, Blazar, Hogan, 2018; Mudzimiri, Burroughs, Luebeck, Sutton, \& Yopp, 2014). Grant (2012) suggests that the purpose of coaching is to make determined change within a specific environment, such as improving mathematics teaching for improved learning in classrooms (Brosnan \& Erchick, 2010; Campbell \& Malkus, 2013). Polly, Mraz, and Algozzine's (2013) synthesis of empirical literature about coaching discussed change and offered a "theory of change for improving mathematics outcomes for all students" (p. 298). The theory proposes that coaches' professional learning should be focused on mathematics content and pedagogy and be connected to the teachers' classrooms in order to change mathematics teaching practices. Improving mathematics outcomes for students in this theory emerge from teachers improving their teaching within their classrooms when coaching includes solving problems as part of planning, analyzing students' mathematical thinking, and collaboratively reflecting on school mathematics. However, Campbell and Malkus (2013) made clear the importance of mathematics specialists (i.e., coaches) training in mathematics content, pedagogy, and leadership when the expectation is to change mathematics teaching and learning through professional development approaches, such as coaching.

In this study, we attempted to understand what impact professional development tasks would have on coaches' training as they approached the end of a 3-year mathematics specialist program. The participants of the study were serving as school-based mathematics instructional coaches in Grades 3-8. The transition from teacher to coach appears simplistic but is often challenging because the knowledge and skills for teaching mathematics well are vastly different from those of a mathematics specialist (Chval et al., 2010; Ellington, Whitenack, Trinter, \& Fennell, 2017). This research focuses on how strategically designed professional development tasks 
influence novice mathematics specialists' learning about: a) the connections between their mathematical understanding and their interpretations of student work; b) their own understanding of probability concepts; and c) their leadership skills for coaching.

\section{Background and Rationale}

\section{Who is a Mathematics Specialist?}

Mathematics specialists are often chosen due to their success as mathematics teachers, which may center on content knowledge, best practices, or even student test results. However, in most instances, these teachers are "ill-prepared for many of the responsibilities and relationships" they must manage once hired as a mathematics specialist or coach (Fennell, Kobett, \& Wray, 2013, p. 173). "[Elementary Mathematics Specialists] EMS professionals need a deep and broad knowledge of mathematics content, expertise in using and helping others use effective practices, and the ability to support efforts that help all students learn important mathematics" (AMTE, 2013, p. 6). In this instance learners of mathematics includes children (i.e., students) and adults (i.e., teachers, administrators, and other leaders including coaches) (AMTE, 2013). The EMS standards and recommendations for mathematics specialists programs are delineated into three areas: (1) content knowledge for teaching mathematics; (2) pedagogical [and andragogical (i.e., for adult learners)] knowledge for teaching mathematics; and (3) leadership knowledge and skills (AMTE, p. 9). The mathematics specialist program reported on in this paper has coursework strands in each of these areas to help develop and support strong mathematics coaches.

\section{Theoretical Perspectives and Background}

The literature about coaches' development is limited (Sutton, Burroughs, \& Yopp, 2011), and we posit that their progress is similar to that needed for teachers. One primary difference between these two groups is that coaches' or mathematics specialists' work involves children and adults as mathematics learners. The theoretical concerns begin by considering the teacher development literature with emphasis on mathematics content and pedagogy. However, when we describe teacher learning in this section, our focus remains on coaches and their development to serve in this role.

We offer an overview of pedagogical content knowledge and worthwhile mathematical tasks for developing mathematical understanding for all learners (i.e., children and adults) with a lens from a practitioner perspective. We then transition to the specific mathematics of probability, which is the focus for this study and describe challenges identified in the literature related to learning probability. These areas provide the theoretical foundations upon which this study was designed and professional development tasks developed.

Research has provided the mathematics community with a great deal of attention to knowledge as it relates to teaching mathematics and preparing novice or experienced teachers to carry out instruction (Carpenter, Fennema, Peterson, \& Carey, 1988; Hill, Schilling, \& Ball, 2004; Peterson, 1988; Peterson, Fennema, Carpenter, \& Loef, 1989; Shulman, 1986, 1987; Wilson, Shulman, \& Richert, 1987). In some instances, teachers have strong content knowledge but weak pedagogical knowledge or vice versa. Shulman (1987) introduced the teacher education community to the notion of pedagogical content knowledge needed for teaching, often interpretted as the intersection of these two types of knowledge. He indicated this knowledge "represents the blending of content and pedagogy into an understanding of how particular topics, problems, or issues are organized, represented, and adapted to the diverse interests and abilities of learners, and presented for instruction. Pedagogical content knowledge is the category most likely to distinguish the understanding of the content specialist from that of the pedagogue" (p. 8).

For years, teacher professional development has focused on teacher satifaction and change rather than teacher learning (Desimone, 2009). The professional community has long established characteristics of valuable professional development, such as being sustained over time, creating opportunities for individual and group reflection/inquiry into practice, and embedding learning into teacher work (Abdal-Haqq, 1995, p. 1). Putnam and Borko (1997) identified four key elements including:

- treating teachers as active learners who construct their own understanding and knowledge;

- empowering teachers and treating them as professionals;

- $\quad$ situating teacher education in classroom practice; and 
- treating teachers as they expect teachers to treat students.

One means to accomplish these critical professional development characteristics is by offerring courses that blend mathematics and pedagogy where learners can engage in mathematical tasks that afford rigourous learning.

Promoting professional development centered on adults as active learners can be accomplished through implementation of worthwhile tasks used to develop content-specific pedagogical knowledge (Hill, Ball, \& Schilling, 2008; Silver et al., 2007; Silverman, \& Thompson, 2008). The idea of worthwhile tasks was introduced in the Professional Standards for Teaching Mathematics (NCTM, 1991) and a primary aspect of these tasks is that they leave mathematical residue - understanding of substantive mathematical ideas. Van de Walle, Karp, and Bay-Williams (2013) articulated the characteristics of worthwhile tasks for practitioners where such tasks can be used to teach mathematics through problem solving. These features include accessibility to all learners, mathematics serving as the engaging element of the task, and expectations of the learner to justify and explain his/her thinking and solution (see also, Smith \& Stein, 2011). In addition, Van de Walle and colleagues (2013) describe worthwhile tasks as not easily solved using straightforward approaches; having contexts that do not distract from the mathematics; requiring student reliance on their existing mathematical understandings; and needing careful planning to prevent facilitators from diminishing cognitive demand or giving unneeded help to capable learners.

Over time, much has been learned about mathematical tasks with respect to developing mathematics understanding. This may include characteristics of tasks for learning (Hiebert et al., 1997; Stein, Smith, Henningsen, \& Silver, 2000), the relationship between tasks and mathematical discourse (Boaler, 2008; Smith \& Stein, 2011), and the role of task implementation and learning (Ainley, Pratt, \& Hansen, 2006; Berry, Bol, \& McKinney, 2009; Doerr, 2006; Henningsen \& Stein, 1997). Van de Walle et al. (2013) described features of problems for learning where learners must perceive such problems as "problematic" (p. 35). While these features for worthwhile tasks describe developing students' learning, we assert that these ideas are also germane for adult learners as well. The professional development tasks (PDTs) used in this study were informed by this vision and designed to prepare mathematics specialists or coaches to support teachers of Grades PK-8 based on professional learning literature and research focused on probability.

Research repeatedly suggests that mathematics teachers are under-prepared to teach probability in elementary and secondary schools (Batanero, Godino, \& Roa, 2004; Canada, 2008; Franklin, \& Mewborn, 2006; Chick, \& Pierce, 2008). Teachers may not have training in theoretical or applied probability and the pedagogical knowledge suitable for teaching algebra, geometry and other branches of school mathematics does not always apply in teaching probability (Batanero, \& Diaz, 2012). Therefore, it is essential to develop training tools that are specifically designed to enhance teachers' content knowledge and pedagogical knowledge in teaching probability (Steinbring, 1990; Stohl, 2005). The design of the tasks used in this study were informed by research on probability learning, in particular the unique misconceptions revealed by young and adult learners studying probability. Shaughnessy (1992) identified that when reasoning in a probability context, learners often do not rely on the mathematical definition of probability concepts; instead, their thinking is largely influenced by their views of the representativeness, availability and other non-mathematical aspects of data, which lead to bias and errors in their judgment (Tversky \& Kahneman, 1974). Such a scheme does not only apply to elementary and secondary school children, but also is widely observed among older learners and mathematics teachers (Albert, 2003; Biehler, 1990). In order for mathematics coaches to facilitate conceptual probability learning, they must comprehend authentic probability concepts and ideas rather than focusing on the intuitional meanings or memorized mechanical procedures. The worthwhile PDTs used in this study served such a purpose. The role of probability-focused worthwhile PDTs and the research design adopted for this study are described in the next section.

\section{Methodology}

\section{Design and Research Questions}

This qualitative research study focused on coaches' engagement with worthwhile PDTs comprised of problem solving, analyses of student work, and individual and collaborative peer reflections. These PDTs were used as an intervention to investigate the following research questions: 


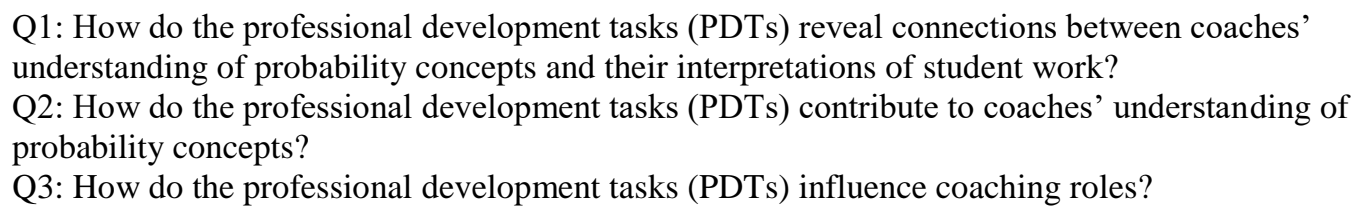

The study is a design experiment (Schoenfeld, 2005) that includes a cycle of design, implementation, analysis, and refinement. At the design stage, a set of PDTs were conceptualized and created based on teacher development, tasks, and professional development literature and theories about probability learning. For implementation, the PDTs were used with mathematics coaches enrolled in a graduate-level course as part of a Mathematics Specialist Program (MSP). Several brief episodes from the implementation are described to illustrate the intervention process and coaches' experiences with the probability-based worthwhile PDTs. Qualitative analyses using coaches' reflective writing from multiple data sources were used to determine the effects of the PDTs on their own mathematical understandings and in relation to their coaching practices. During the course, tasks were refined to improve coaches' reflections for learning using follow up questions (see Case $I V$ for an explicit example of how such questions were used). After reporting the findings, suggestions for refining the overall PDT structure based on our learning from this experiment are offered.

The Mathematics Specialist Program (MSP) was designed using a mini-cohort structure - small groups (3 or more) of coaches from a single school district go through the program together. The mini-cohorts were combined with other mini-cohorts from other districts so that courses had sufficient numbers of students; a strategy for growing this program's enrollment. A benefit for students was a structure that afforded program students peer groups within their school district and access to others from nearby school districts similarly engaged in mathematics leadership with whom they developed professional relationships. These relationships emerged early on, such that instructors readily observed collegial interactions among students before, during, and after classes beginning as early as the first course. Instructors also observed students developing mathematical autonomy - reliance on their own thinking and no longer seeking validation from the instructor. The courses used instructional strategies for developing mathematical autonomy, such as creating opportunities for learners to develop and communicate good mathematical explanations, valuing all contributions, and seeing errors as opportunities for learning (Cobb, Gresalfi, \& Hodge, 2009; Hodge, 2006; Hufferd-Ackles, Fuson, \& Sherin, 2004; Nasir, 2002).

This study, developed around a probability and statistics graduate-level course designed for PK-8 mathematics specialists, focused only on the probability aspect of the course. This course is one of five mathematics pedagogy courses in the MSP focused on key content strands of number, rational numbers and proportional reasoning, algebra, geometry \& measurement, and probability \& statistics. One researcher was the instructor of the probability and statistics course, while other researchers participated in the analysis processes to minimize the potential for bias and improve the validity of the findings. All researchers taught this group at least one time for other courses.

\section{Participants}

Participants of the study were coaches enrolled in a probability and statistics mathematics pedagogy course with more than three years of mathematics teaching experience at the elementary or middle level in a public school from one district. In the course, the PDTs were used to engage coaches in professional learning with their peers. We postulated that the task intervention would support the development of knowledge needed for coaching mathematics content, pedagogical content, and leadership dispositions and skills.

The four coaches, who are the focus of this study, were consenting participants. They were made aware that their work could be used for this study and were instructed on how to opt out of the study at any time with no negative consequences; this study and the opt out process were approved by an Institutional Review Board (IRB) sanctioned by the researchers' university. The participants were a purposeful sample because they were near completion of the MSP and possessed an extensive foundation for coaching as recommended by Campbell and Maukus (2011). These participants were completing their final semester of the MSP and upon completion of this specific course and a required internship, they would be eligible to apply for the PK-8 Mathematics Specialist endorsement from the state's Department of Education.

The coaches shared similarities including: a) working in the same school district for multiple years; b) serving their second year as a coach after being recognized as an effective mathematics teacher; and c) implementing a 
specific classroom-embedded coaching model designed to improve mathematics teaching and learning (modeled after MCP, 2014). These similarities minimized challenges related to carrying out the PDTs with students. The coaches had differences including: a) the number of schools they supported; b) grade levels coached; and c) the match or mis-match of coaches' teaching experience with the grade levels coached. One coach was assigned to a school full-time and the other three coaches split their time between two schools. Of the four coach participants, they held different teaching credentials - three were elementary general teaching endorsed and one was secondary mathematics teaching endorsed. Two of the elementary licensed teachers were assigned as coaches for elementary schools. The third elementary licensed teacher and the one secondary licensed teacher were each assigned to coach at one elementary and one middle school. These differences afforded sufficient variability among the participants so that anomalies related to their coaching assignments might emerge.

The coaching model implemented valued and encouraged coaches to collaboratively support teachers to develop reform-oriented mathematics by sharing their knowledge of ideas such as problem-based learning (e.g., Smith \& Stein, 2011); incorporate mathematical processes and practices (e.g., CBMS, 2012; CCSSI, 2010; NCTM, 2000) in daily mathematics instruction; and to create student-centered learning environments for developing mathematical understanding (Hiebert et al., 1997). This type of coaching relies on individuals who are practiced learners of mathematics, possess insight into creating opportunities for learning without diminishing cognitive demand for learners, and operate as transformational leaders. This type of leadership in the context of this coaching model advocates for coach leaders to engage as learners who interact with teachers as peers and promote those teachers to develop as leaders of learners (definition adapted from Bass, 1990).

\section{Design of Professional Development Tasks (PDTs)}

Mathematics Teaching Today (Martin, 2007) and the Principles to Actions (NCTM, 2014) publications suggest that teachers need knowledge of mathematics content, pedagogy, and student mathematical learning in order to implement worthwhile mathematical tasks. Similarly, the Standards for elementary mathematics specialists (AMTE, 2013) addresses expertise mathematics leaders should possess including content knowledge for teaching mathematics, pedagogical knowledge for teaching mathematics, and leadership knowledge and skills. In these areas, a deep understanding of mathematics, specialized knowledge about teaching, learners, curriculum, and assessment also are characteristics of these mathematics professionals. Having a solid foundation of such knowledge and proficiency enables effective task implementation to promote teacher reflection and analyses of mathematics and student understanding. More specifically, Carpenter and Lehrer (1999) provide five types of mental activity to consider in developing teacher understanding: (1) constructing relationships, (2) extending and applying mathematical knowledge, (3) reflecting about experiences, (4) articulating what one knows, and (5) making mathematical knowledge one's own. Again, researchers consider teacher development literature through a lens for coach development.

The tasks designed for this study were informed primarily by mental activities (Carpenter and Lehrer, 1999) in points 2-4 - extending and applying, reflecting, and articulating. The PDTs should be "worthwhile" (Van de Walle, Karp, and Bay-Williams, 2013) and afford opportunities for coaches to investigate mathematical concepts, apply their own mathematical understanding to analyze student work, and reflect on and articulate their own understanding and that of their students; essential steps in strengthening their content and pedagogical content knowledge. Ten PDTs were created for the course and coaches typically worked on one PDT per week throughout the semester. The tasks were situated within Grades 3-8 probability concepts, such as sample space, number of possible outcomes, sampling survey, and dependent and independent events.

The structure of the PDTs provided coaches opportunities for identifying strengths as well as correcting their existing misconceptions about probability. This process of solving problems and collaboratively reflecting on their solutions with peers revealed coaches' understandings and misconceptions about probability. These opportunities also afforded coaches experiences similar to those that students might work towards developing mathematical understanding; an experience that enhances coaches' understanding about learners and learning that develops dispositions for mathematics leadership - nurturing collaborative, reflective, and continuous mathematics learners.

The PDT structure has three components - (1) coach problem solving, (2) observation of student problem solving and analyzing artifacts, and (3) individually and collaboratively reflecting on the problem solving process. In the first component, coaches solve probability problems and reflect on their solutions in writing. In this case, the instructor poses follow-up questions used to evaluate understandings for each problem including a) identify the key concepts addressed by the problem; b) predict how students in different grade levels might 
solve the problem; and c) speculate about student rationales. Responses to the follow-up questions revealed insight into coaches' mathematics knowledge for teaching (Ball, Hill, \& Bass, 2005) together with the depth of coaches' content knowledge and student thinking. The problems incorporated into the PDTs were problematic and challenging for both children and adults. They were selected, in part, to reveal nonmathematical probability reasoning and other challenges identified in the literature (e.g. Batanero, \& Diaz, 2012; Shaughnessy, 1992; Stohl, 2005). One such example is as follows.

If Ryan randomly picked a name from the list of NBA players, which would he be more likely to choose?

$\begin{array}{llll}\text { A) a white man } & \text { B) a black man } & \text { C) a white tall man } & \text { D) a black tall man }\end{array}$

The probability concept of interest for this question is maximum sample size, which would be the most likely option. This problem revealed nonmathematical approaches for probability reasoning, such as, relying on observed representativeness (Shaughnessy, 1992; Tversky, \& Kahneman, 1974). Many learners, children and adults, chose Option D, suggesting that most athletes in America's National Basketball Association (NBA) are tall and black; an image "closest" to what many might envision.

Next coaches select one problem for at least two Grades 3-8 students to work on and solve. The purpose of this field-based component affords coaches practice observing and questioning students to gain understanding about students' mathematical thinking and to develop dispositions and skills associated with mathematics leadership. The coaches encouraged students to provide explicit explanations through questioning them about the "what?" and "why?" of their mathematical thinking and solutions. Coaches were allowed to help the students understand questions, but not provide instruction on how to solve problems. Coaches analyze student work searching for similarities and differences in student artifacts, e.g. evidence of mathematical understanding and problem solving strategies; and then record their perceptions about each student along with comparisons.

Lastly, discussions during class sessions were facilitated by the course instructor on coaches' problem solutions and discoveries from working with children as well as analysis of their work. The instructor established a safe environment for this type of reflective sharing by valuing errors and treating them as pathways for improved understandings and learning, and graded evaluations were not always based on correct answers, even when assignments were related to problem solving. Coaches shared artifacts with the class from the PDTs comprised of multiple approaches and solutions (coaches and students) and the analyses and reflections of student work. The instructor afforded opportunities for discussions in small groups or whole-class conversations to determine accuracy, appropriateness, and completeness of problem solutions and student work analyses. The instructor's role was as a guide to clarify confusion about mathematics concepts and to ensure that key aspects of student work were noticed. It was anticipated that this type of intervention could provide coaches opportunities to:

- $\quad$ engage in solving problems that address key probability concepts for Grades 3- 8;

- closely observe and question students as they work on problems that the coach had previously worked to gain insights about students' learning trajectories; and

- $\quad$ note how their understanding of probability influenced their interpretation of student work.

In this type of PD environment, the instructor did not expect to resolve every content misunderstanding coaches demonstrated during the short intervention period. However, she presumed that by providing coaches experience with problem solving, student work analyses, and peer critics, they might recognize gaps in their knowledge and the consequences such gaps might cause. Thus, instruction attempted to provide the type of environment where coaches came to value working collaboratively to strengthen their mathematics understanding. This type of learning centers around experiences Shulman (1987) might refer to as pedagogical content knowledge and promotes the ideas Putnam and Borko (1997) articulate as necessary for effective professional development experiences.

\section{Data and Analysis}

Implementation of coding for this study occurred at two levels - one focused on the participant's role as a learner and the second focused on his/her role as a coach. The first phase centered on tasks the coaches solved for their own learning followed by selecting student work representing the same tasks. At this level, observation and notes from course discussions, reflective narratives for task assignments, and portfolio reflections were used. For the second coding segment, attention was on the degree to which tasks impacted participant perceptions of their role as mathematics coach. Evidence for this coding was generated by questionnaires and 
portfolio entries. In both phases, researchers generated themes based on participant data as well as how the data related to the theoretical framework on teaching and learning mathematics with understanding (Carpenter \& Lehrer, 1999).

Additionally, coaches' portfolio and questionnaire responses were used to analyze the influence of the PDTs on their practices. The portfolio, a requirement for all mathematics pedagogy courses in the MSP program, was comprised of numerous artifacts, including: a) descriptions of significant mathematical concepts mastered or refined; b) worthwhile task collections for engaging children and adults in mathematics learning; and c) a philosophical statement about mathematics teaching and learning. Guidelines for the portfolio components are provided at the beginning of each course, but are sufficiently broad to allow for coaches' individuality and variability in mathematical foundations. Different components of the portfolio are collected and returned with feedback from the course instructor. Because the portfolio for this course was the fifth iteration of their philosophy about mathematics teaching and learning over almost three years, we believed this would be a rich source of data for this study.

The questionnaire gathered coaches' input about how the PDTs influenced their own mathematical knowledge, understanding of student thinking, understanding for mathematics teaching, and their role as a mathematics coach. They were to support their responses to each question with specific examples. The questionnaire afforded the opportunity for coaches to reflect upon and respond to questions that asked explicitly about the influences of the PDTs, which improved the robustness of the overall data corpus used for this study. The probability and statistics portfolio was collected near the end of the course and the questionnaire was administered during the last class session.

Analysis of data used interpretive qualitative approaches, document analysis, and case study techniques (Stark $\&$ Torrance, 2005) to address the research questions. Triangulation was used for analysis and data throughout this study - multiple researchers analyzed the same data and multiple data sources were used to warrant claims; practices that enhanced the validity of the analysis and findings (Lather, 1993). Due to the nature of the qualitative research design, data analysis was inductive and comparative in the way it proposed to develop themes or categories that cut across the data (Merriam, 2009). As data was reviewed, clusters or units that shared traits were generated and categories identified. Using the intervention previously discussed, along with portfolio reflections and questionnaires, researchers searched for patterns to identify themes that corresponded with each other. These themes helped respond to the research questions that guided this study on how probability-based worthwhile PDTs influenced coaches as learners and leaders.

\section{Findings of the Interventions}

\section{Cases of Probability Task Interventions}

The following cases illustrate several probability problems used in PDTs and the coaches' responses. We posit that a substantive portion of the coaches' professional learning emerged from collaborative reflections with peers about coaches' and students' problem solutions, explanations, and analyses of student work. In this section, the focus is on the first research question - "How do the PDTs reveal connections between coaches' understanding of probability concepts and their interpretations of student work?" We specifically selected three cases where coaches' probability solutions lacked accuracy for the problem they chose for students to solve and one case where the solution was accurate. These examples exemplify the types of relationships we found between coaches' mathematical understandings or misconceptions and their interpretations of student work.

\section{Case I: Fragile understanding $\rightarrow$ Misconception acceptance}

One important concept in school probability is the independence of events. Learners are taught the definition of independence, but understanding is not guaranteed and they may not be able to apply it correctly when problem solving. A typical misconception occurs due to the confusion of the combination of outcomes with the sequence of outcomes, where the order of the outcomes only matters in the latter case. We provided the following problem to the coaches to highlight this issue.

Randomly flipping a coin 10 times, which of the following 2 results is more likely to happen (H-Heads, T-Tails; results are listed in order.)?
A. $\mathrm{HHHH} \mathrm{H} \mathrm{H} \mathrm{H} \mathrm{H} \mathrm{H}$
B. Н T T H T H T T T H 
One coach's response below revealed this common misunderstanding. The coach chose B for the problem and explained that:

The theoretical probability is near 50/50 so there would minimally be a few of each, heads or tails. Experimentally it is rare that all heads would be flipped.

The coach provided the problem to a $7^{\text {th }}$ grader whose response is shown as follows.

Result 2 because if you flip a coin 10 times you won't just get heads. You would get both heads and tails.

When reflecting on the student's response, the coach stated:

When I asked the student to explain the answer further, the student stated that the question was asking how many times the coin would land on heads or tails. ---- This told me that the student had a good understanding of the question.

When I asked her why, she stated that there are 2 sides and the coin probably is not going to land on heads every time. ---- This told me that she has reasoning skills and possibly some experience with this model of questioning in the past.

When I asked her why not, she stated that there was a chance to get all heads but that it was not likely. But in the end you don't know if it will be heads or tails. This told me that she understood the probability at the elementary level where they were taught to compare on a number line with indicators as seen below.

\begin{tabular}{|c|c|c|c|c|}
\hline 1 & l & 1 & & 1 \\
\hline O impossible & dinlikely & equally likely & likely & $\left.1\right|_{\text {certain }}$ \\
\hline
\end{tabular}

The coach's reflection about the student work provided information about her mathematical understanding. The reflection confirmed that the coach only considered the frequency of heads and tails in the outcomes (as a representative feature), while the order in which they appear was overlooked. Furthermore, the coach also revealed the mathematical model, i.e. the intuitional understanding of probability at early elementary level, on which she relied in evaluating student understanding. This offered a clearer picture of the basis for her judgment. This case exemplifies how limited content understanding led to a misinterpretation of student work and makes explicit both the consequence and importance of developing a thorough understanding of the mathematics being taught. Had the coach possessed a more complete mathematical understanding of this concept, the results would have been different.

\section{Case II: Fragile understanding $\rightarrow$ Student error misinterpreted}

The following problem was included in one of the problem sets in order to enhance coaches' understanding of possible outcomes of an event.

A sandwich shop offers 6 different types of meat and 5 different types of vegetables. You must choose one type of meat for your sandwich. However, you can choose up to 5 different types of vegetables to put on the sandwich (It is also ok if you don't want any vegetables). How many different combinations of meat and vegetables can you order for your sandwich?

The problem involves two different mathematical structures: choosing 1 out of $n$ and choosing up to $n$ out of $n$. The purpose of the problem is multifaceted: a) to find the number of possible outcomes for the two types of structures; b) identify the different operations for each structure; and c) make connections among the structures, operations, and a specific and simplistic context to strengthen the mathematical understanding. The following coach's work (see Figure 1) demonstrates a likely error when working on this type of problem. 


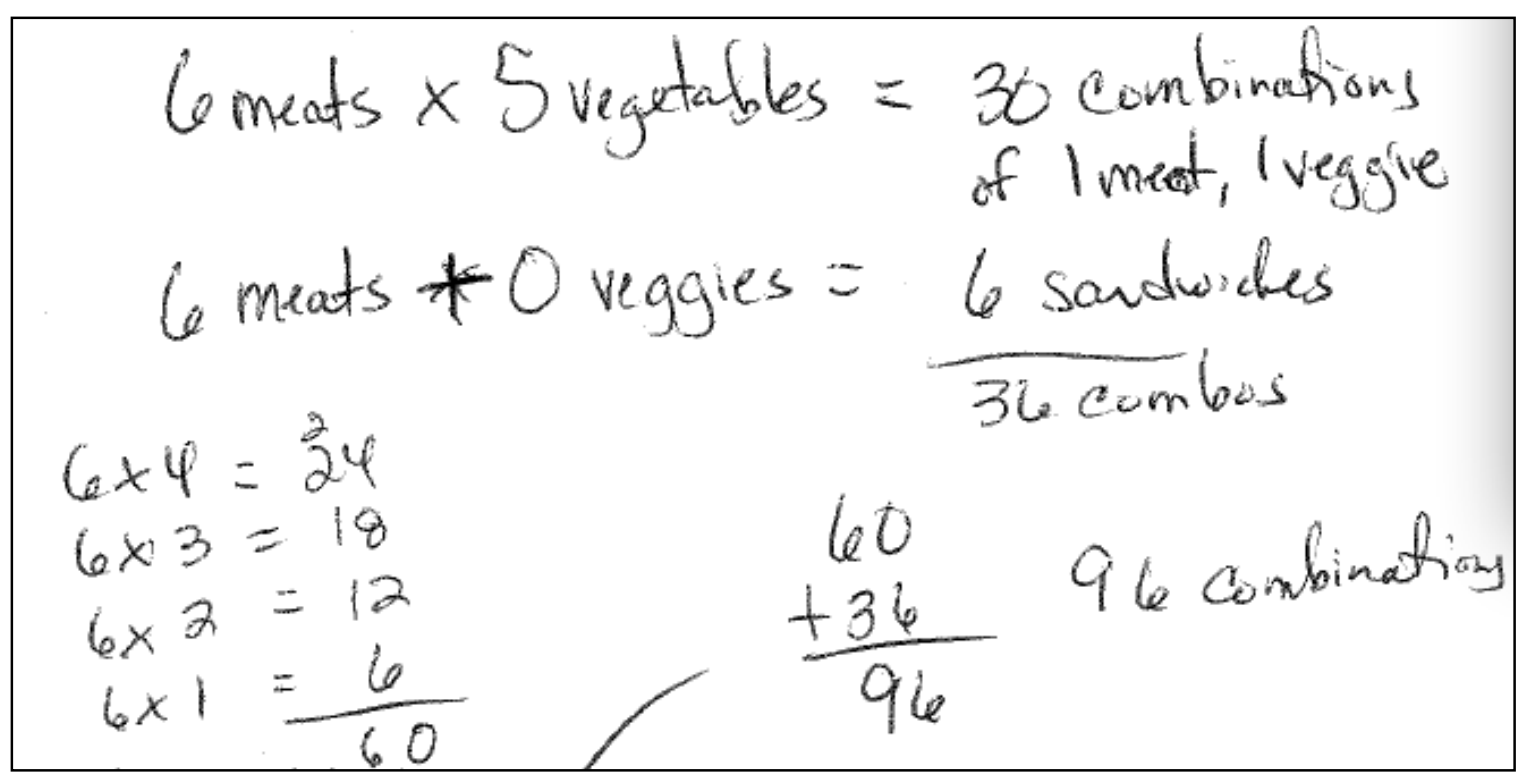

Figure 1. One coach's solution to the sandwich problem

The coach was aware that there is a difference between the two types of structures. First, she tried to break down all possible outcomes into different cases by the number of vegetable types included on the sandwich. Then she tried to calculate the number of possible outcomes in each case. The conceptual error was introduced when she attempted to add the meat and no vegetables option. There appears to be some cognitive dissonance around the mathematical statement for the number of possible no vegetable combinations as evidenced by the overwritten operation symbol. She first chose multiplication as with the other cases but had difficulty making sense of the result. So she changed the operation to addition, which gave her a correct number sentence and an answer of 6 sandwiches which seemed reasonable. The context enabled her to know this with confidence. However, selecting addition as the operation is not mathematically justifiable. This coach lacked an understanding of the difference between the two types of mathematical structures and awareness of connections between the two structures and operations needed for finding the number of possible outcomes.

After working through the problem herself, the coach gave the same problem to a student, observed the student's problem solving process, and analyzed the response. This grade 5 student's response is shown in Figure 2.

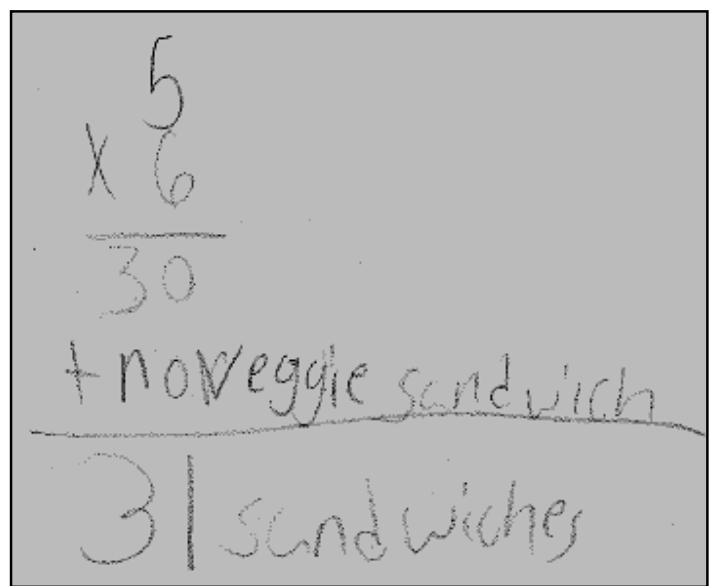

Figure 2. One student's solution to the sandwich problem

In the coach's analysis of this student's work, she wrote:

I learned that student 1 used the formula that he was taught in $3^{\text {rd }}$ grade, such that 6 meats $\times 5$ veggies $=30$ combos. He was able to think beyond that enough to include 1 more option for no veggies, but he did not apply that option to each meat. Nor did he realize that each meat could be paired (also) with 4, 3, 2, 1 veggies 
The coach's explanation revealed that she was familiar with the multiplication formula that is widely adopted to solve possible outcome problems encountered at the elementary level. She correctly pointed out the error when the student suggested there is only one possible "no veggie" sandwich. However, she mistakenly believed that the formula would calculate the number of possible combinations when there is 1 type of meat and 5 types of vegetables. Therefore, when the student wrote down $5 \times 6$, she immediately believed that the student correctly considered the situation when there were 5 types of vegetables and 1 out of 6 types of meat by adopting the formula. Then she suggested that the student made a mistake because he did not realize that "each meat could be paired (also) with 4, 3, 2, 1 veggies".

Both the coach and the student demonstrated an intuitional or doctrinal (as opposed to conceptual) use of multiplication. Neither attempted to contemplate what the 30 combinations they obtained were and what the operation $5 \times 6$ denoted (e.g. Does it mean 5 groups of 6 or 6 groups of 5 ? What are the groups and what is in each group?) The coach did not recognize that she and the student's errors were rooted in an instrumental understanding (Skemp, 1976/2006) of finding possible combinations tied to operations and formulas. Instead, she had the false belief that the student missed a few cases in counting the possible outcomes. The above case demonstrated how the coach's content limitations influenced her ability to make accurate analysis of student errors. When student errors are misdiagnosed, they cannot be corrected or used to build stronger understandings of concepts.

\section{Case III: Fragile understanding $\rightarrow$ Promising approach unrecognized}

The following problem focuses on making a prediction based on the result of an experiment.

At a factory that produces doorknobs, a batch of 1000 doorknobs has just been produced. To check the quality of the doorknobs, a random sample of 36 doorknobs is selected to test for defects. Of these 36 doorknobs, 2 were found to be defective. Based on these results, what is the best estimate you can give for the number of defective doorknobs in the batch of 1000 ?

A coach provided the following response to the problem.

In order to get an appropriate sample for a thousand doorknobs, depending on confidence interval used, somewhere between 250 - 950 doorknobs would be tested. If 2 out of 36 were defective, that means that 1/18 were defective. But because the sample size is so small, an estimate based on this calculation would not be reliable.

... I am uncertain of what students in elementary school would respond with when faced with this problem. This problem would not be representative of anything that they would have been asked to think about. If I had to choose a possible response (at any grade, 3-5) I would say that if 34/36 were not defective, then 998/1000 would also not be defective.

The coach demonstrated some level of understanding in the response. She correctly pointed out that 1/18 of the tested doorknobs were defective and was aware that the larger the sample, the more reliable the estimate. However, there were some tenuous statements, for example, testing 250-950 of the 1000 doorknobs seemed beyond conservative and then claiming that upper elementary children would never be asked to consider such a problem seems shortsighted and perhaps suggests a fragile understanding of the curriculum. This problem involves proportional reasoning and is a key mathematics concept for children in Grades 3-5.

In order to better evaluate what the coach knew about the problem, we looked at her analysis of two fifth graders' work. One student found that for every 36 doorknobs, there would be 2 defective ones. So she attempted to repeatedly subtracting 36 from the 1000, and adding the 2 s to make an estimate. She did this 3 times when she saw about 100 doorknobs were removed and jumped ahead to make a quick estimate. The coach was able to understand the student's strategy. She stated that:

This student was nervous about trying the problem but then proceeded to show a strategy. She made clear to me that every time she subtracted 36 from the total, two more would be defective, so for every 100, 6 would be defective, so 60 per 1000. I was amazed by her thinking.

The other student was less explicit in his written work (see Figure 3). 


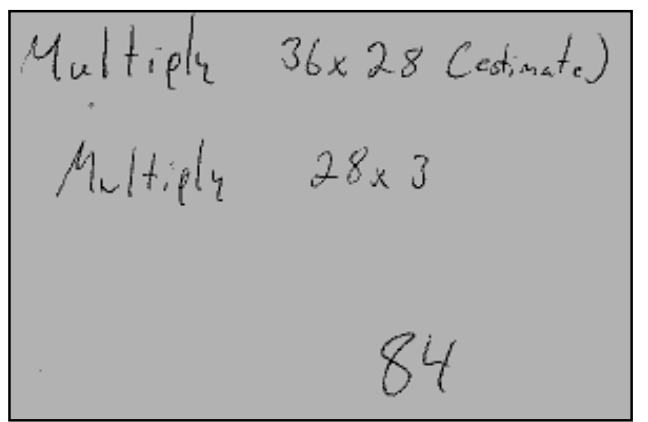

Figure 3. One student's solution to the doorknob problem

Notice that $36 \times 28$ is equal to 1008 , which is the closest multiple of 36 to 1000 . We also suspected the student might have accidentally written 3 for 2 in his solution. When reflecting on this student's work, the coach suggested:

This student stated that he didn't understand the problem. When I asked him to try, he used a calculator to multiply $36 \times 28$, with 36 representing the doorknob samples. But he couldn't explain in any way that made sense to me. He also couldn't explain the 3. The interaction told me that neither of us fully understand the real task.

... "Student $K$ " was essentially frozen at the initial presentation of the problem and had no real way to make sense of the problem.

From the two coach reflections, we believe the coach was unable to transfer what she detected in the sample to the property of the population. She realized that $1 / 18$ of the sample doorknobs were defective, but was unable to develop a strategy for estimating the number of defective doorknobs in the set of 1000 . In her prediction of what an elementary student might do, she did not mention anything about proportional reasoning. Instead, she envisioned that students would believe there would always be 2 defective doorknobs regardless of the size of the entire set. Two Grade 5 students solved the problem, one student was explicit in explaining a strategy to link the property of the sample to the property of the population; the coach was impressed by the student's approach. The other student strategy may have been promising; however, the student was less explicit, in writing and verbalizing, about his strategy and the coach was unable to support the student. The coach claimed that the student "was essentially frozen at the initial presentation of the problem and had no real way to make sense of the problem." This case explicitly shows how listening to students' explanations can help illuminate their understandings and can sometimes teach adults things they had not contemplated. The first student work example showed a coach learning from a student. The second example showed how less conceptualized understanding can limit opportunities for seeing a student's potential. This is especially true for students who are challenged to communicate their mathematics, as was the case in this example and for many students in mathematics classrooms across the world. The take away is that children must be afforded opportunities to communicate their mathematical ideas.

\section{Case IV: Solid understanding $\rightarrow$ Accurate projection/promising plan}

The spinner model is a common tool for introducing probability. Students are often asked to determine the likelihood of the pointer landing on certain sectors of a circular region. An instrumental understanding suggests finding the proportion of the area of the slices to that of the entire spinner. However, this problem requires more flexible relational understanding (Skemp, 1976/2006) which challenges that approach. The following problem highlights this issue.

The pointer of a spinner is placed at a location other than the center of the disk, as shown in the figure. Is it more likely that the pointer lands on the grey area or the white area after it is spun? Why?

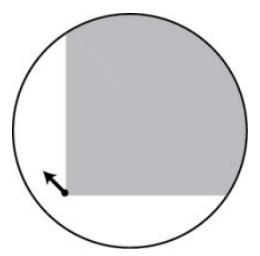


One coach drew a smaller circle around the pointer and provided the following response to the problem.

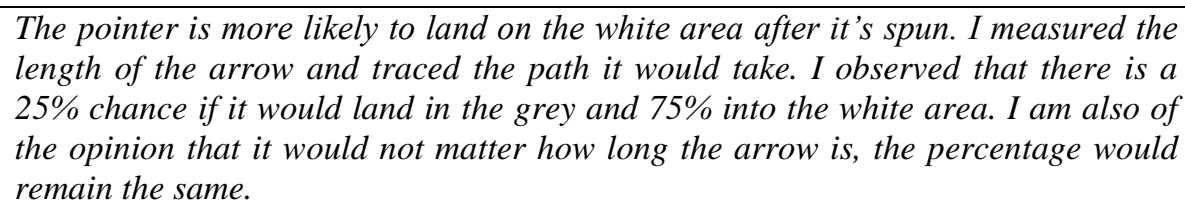
length of the arrow and traced the path it would take. I observed that there is a $25 \%$ chance if it would land in the grey and $75 \%$ into the white area. I am also of the opinion that it would not matter how long the arrow is, the percentage would remain the same.

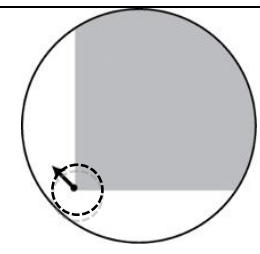

We provide some follow up questions that were a part of this task: What kind of misunderstanding might students exhibit when solving this problem? The coach suggested that students might mistakenly choose grey since it has a larger area. When asked about possible approaches to address such misunderstanding, the coach suggested constructing models with arrows of different lengths and experimenting with the models. The coach stated that students should pay particular attention to the path of the pointer and collect data on where the pointer landed to consolidate their thoughts.

The coach was probably not prepared to explain the problem using more advanced probability concepts such as probability density. Nevertheless, it was clear that the coach was able to realize that it was not a simple linear relationship between the size of the area and the chance of the pointer landing on it, which might be a common student misconception. Finding the geometric measure that can determine the likelihood is the key idea for this problem. The coach successfully identified and isolated a familiar construction within the model and used existing knowledge of the familiar construction to solve the problem. In addition, the coach proposed promising direction to target student misunderstanding that was reinforced by the "uniform" spinner models often used in standard curricula. In the coach's reflective writing, the coach encouraged student exploration by using pointers with different lengths. During the class discussion, the coach shared the idea of changing the spinner, which incited other suggestions from peers for modifying the problem, such as, changing the location of the pointer and the shape of the spinner. These ideas, if enacted, could expand the learning of mathematics related to the spinner model such as area, length, angle, and likelihood.

The coach provided the problem to a $3^{\text {rd }}$ grader and recorded the student's work. The student first responded " $I$ think it is more likely it is going to land on gray because mostly all you see is gray in the picture," which was what the coach expected from most students. The coach encouraged the student to trace the path of the pointer and after exploring with that approach, the student claimed that "after thinking about it I now think it will land on white."

It was unclear if the student fully understood the problem at the end due to the lack of record of what occurred. However, the coach's direction on more carefully analyzing specific changes that relate to event, i.e. the path of the pointer, rather than relying on obvious but maybe unrelated factors, such as the area, seemed to have an impact on the student's judgment. This case demonstrated that adequate content knowledge of a topic helped coaches identify where common student misconceptions may exist and what types of instruction may be helpful to address such misconceptions.

\section{Summary of Task Interventions}

The four cases illustrated that when coaches possessed inadequate or inaccurate content understanding, they were not well positioned to understand and make accurate interpretations about mathematical understanding of student work. Specifically, from this study, we found that limited content knowledge led to one of the following: a) incorrect student responses might be accepted; b) a promising approach was overlooked; or c) student misconception was misinterpreted. Conversely, when the coach held sufficient content understanding, it enabled the coach to more accurately predict student approaches, to understand student thinking, and to plan for promising intervention in the event when the misconception emerged. We shift focus to the coaches' reflective writings, questionnaire responses and philosophy statements about mathematics teaching and learning from their portfolios. These data sources provided additional insight on how the PDT interventions influenced their mathematics understanding and coaching roles. 


\section{Findings of Reflective Writings}

\section{Coach as Learner}

The search for evidence to document change of coaches' perspectives in understanding probability was critical to answering the research questions. Concentrating on coaches' learning content as it relates to probability was evident in task submissions and portfolio reflective writing assignments about problems they had solved during the course. Individually, coaches identified a wide spectrum of responses about their learning, but taken as a group, collective categories were collapsed into four main clusters: challenging problems, problem solving, multiple representations of problems, and use of real-world problems (relevant to the learner).

Evidence related to "being challenged" in working the probability problems was a recurrent theme across the data. One coach eloquently expressed this by saying, "I have been personally challenged in having to work out the problems," while another indicated, "some problems challenged my thinking." Also evident from the data was that coaches' content knowledge had been stretched in ways they had not imagined prior to engaging with the probability problems. One coach reflected, “. . . showed me that I need to constantly be learning so I can teach others."

However, it was also observed, in some instances, that coaches might not have personalized the learning experience. They indicated that teachers need to study more mathematics; however, they did not explicitly apply this notion to themselves. This raised questions for researchers, as they wanted to determine if coaches saw their own limitations in working with content matters and the need for them to more deeply study the mathematics content. One possible modification for future study is to have coaches reflect on their work for problems and discuss with colleagues prior to engaging students with working on the same problems. We anticipate that this may be more revealing for coaches in understanding their own strengths and limitations in working with content as well as gaining insight into student work.

Enhanced emphasis on problem solving was an emergent theme for coaches working through the PDTs. For example, one coach commented, "The study of probability (and statistics) requires logic and reasoning." While another said, "logic and deductive reasoning were a part of working through problems." In both instances, these descriptors were part of what they referred to as problem solving in mathematics - not knowing the answer to a problem immediately and persevering. In many instances, it was noted that this type of problem solving was not part of their own learning in mathematics prior to teaching. Working through problems that were cognitively demanding, not solved using straightforward procedures, yet accessible, enabled participants to use logic and reasoning coupled with their own sometimes limited mathematical understandings in order to engage in the PDTs. One coach described this as,

I loved so many of the problems that we attempted during this course. Not because of the solution that I arrived at, which was usually incorrect, but rather because of the thinking I was required to do in order to reason through the problems. Sometimes I was so excited about the work I had completed - even after I got to class and discovered that I was wrong again. I really believed that the work was more about the process than the outcome.

While this coach was challenged by the probability content, he still recognized the importance of problem solving as process and not as a right answer, not to diminish that correct solutions are critical for all mathematical learners.

Representation was an emergent theme from the coaches' problem solving and was often related to visual aspects of various problems. One coach expressed that visualizing and drawing diagrams, studying data and trends of graphs helped one "figure out or predict what is going on in the problem." Another coach shared, "I learned quite a few things: visualizing and drawing diagrams works to help figure out what is going on in the problem." The coaches in this study identified with representations to help them make sense of the problems they were attempting to solve. Representations is one of the mathematical process standards (NCTM, 2000) and is described in relation to pedagogical knowledge for teaching mathematics, "EMS professionals must know and be able to construct and evaluate multiple representations of mathematical ideas or processes, establish correspondences between representations, and understand the purpose and value of doing so" (p. 7). Developing the process of representation is critical as a learner of content in order for one to make decisions on how to incorporate the practice into instruction. 
The final theme that emerged for coaches was valuing the influence that problems with real-life contexts made for their learning mathematics. Conversely, problems solved using algorithms and routines like tree diagrams or picking a card out of a deck did not afford them as much meaning. Coaches expressed that their interests were heightened and they could engage more fully in making sense of concepts when problems were situated in reallife contexts. As one participant alluded, studying probability is more than spinning spinners and rolling dice, which show up all too often in school mathematics. Using real-life contexts helped give greater meaning to problems, but also allowed coaches to see how probability can be used to make sense of the world around them.

\section{Coach as Leader}

A questionnaire, administered at the end of the semester, is used as a regular part of evaluating the mathematics pedagogy courses in the MSP. The focus of such an instrument is to reveal what works well for coaches with respect to their own mathematics content development and the pedagogies that help them work with students and teachers. Questions that appear focus on the content area of the course - in this case probability and statistics - and the impact the PDTs had on their coming to make sense of the mathematics as well as student work. These questions have coaches reflect on their role as a coach in supporting teachers to understand and make use of student work. Questionnaire responses suggest that at least two of the coaching roles were influenced by the PDTs - (1) role of mathematics learner and (2) role of leader of mathematics learners. Themes were generated from the questionnaire data related to their role as mathematics coaches and what impact working the tasks had on them as learners but also when they observed and analyzed students working on the same problems. Coding of data generated categories of student-centered problems, time for students to explore problems, flexibility to adapt problems, and discussion of tasks with colleagues.

Coaches' experiences in working through problems prior to posing them to students allowed them to comprehend that for students to engage in such situations, they would need more time to explore and make sense of them. They grew in their understanding that teachers need to be flexible in the way they present and adjust problems used for instruction, which should be interesting and student-centered rather than teacherdirected. Coaches provided evidence of being more responsive to listening to students and trying to make sense of what they say - not just for correct responses but also for incorrect responses. Listening to students is a process that can occur in oral or written form and is promoted in the EMS standards (AMTE, 2013). Traditional instruction has often focused on directly providing "the right" concept or approach rather than understanding what might be wrong with students' existing conception and building knowledge upon existing understanding. Reflecting on what is wrong and acting on this mindset presents challenges in providing coaches with new opportunities of instruction and how to manage this practice in classrooms. One questionnaire response indicated this clearly by stating, "Prior to this class, my ideas about how probability and statistics was learned was more teacher-centered \& less student-centered. This class has guided me to re-image (sic) how I think beyond formulas \& teacher direction." This same coach wrote, "Not all students need direct instruction and can use intuition to develop their thinking."

The personal experience coaches had influenced their perceptions of what their role was in working with students and teachers both. Several important features of a coach emerged throughout this process of individually working problems, presenting the same problems for students to work out, and discussing both instances with peers. Reactions to PDTs included comments such as, "Having time to discuss student work with colleagues helps in understanding what students are thinking." In addition, coaches began to focus more attention on listening to learners' explanations on working problems. "We have to re-image (sic) the material and the way it is delivered and learned... We need to listen to students with a purpose and what they have to say about their understanding - we can come to understand what they know and don't know."

\section{Summary of Reflective Writings}

Several findings emerged from the analyses of coaches' responses to the questionnaires, reflective portfolio writing assignments, and rationales written as part of their solutions submitted for the PDTs. First, the problems posed as part of the PDTs identified coaches' and students' understandings and misunderstandings of specific probability content, which in turn, created opportunities for coach learning. Second, coaches believed the tasks contributed to improving their understanding of student work. Lastly, coaches believed the tasks enabled them to be better prepared to coach - to support teachers and learners using approaches other than telling and modeling. 


\section{Discussion}

This final section reflects on what was learned by summarizing the responses to the research questions while making connections to existing research and practitioner literature. Authors then reflect on the design experiment and offer suggestions for refining the PDT structure based on what was learned from this experiment. Finally, recommendations for future research are presented.

\section{Research Question Responses}

The findings from coaches' responses to the probability-based PDTs were used to address the first research question:

Q1: How do the PDTs reveal connections between coaches' understanding of probability concepts and their interpretations of student work?

The core idea of the PDT interventions the authors designed for coach development is the power of examples and reflections. Coaches were provided opportunities to work on examples of content problems solved by themselves, peers, and students, with opportunities to reflect on the solutions at every step, both individually and collaboratively. It appeared that the PDTs were useful for revealing connections between coaches' understanding of mathematics content and making interpretations of student work. Additionally, the PDTs can be used to support coach development in other ways, including the following:

- Help coach educators and researchers better understand coaches' mathematical understanding through use of the PDT structure;

- Help coaches deepen their mathematical understanding through more experiences solving problems and analyzing their own and students' work; and

- Help coaches recognize the consequences of having a fragile mathematics understanding on their ability to accurately interpret students' mathematical understandings.

Carpenter and Lehrer's (1999) work on teaching and learning mathematics with understanding guided this research in focusing on three key elements of extending and applying mathematical knowledge, reflecting about one's experiences, and finally articulating what one knows. The PDTs positioned coaches to confront their own mathematical knowledge first before they could think about sharing what they knew and how to make use of this knowledge in working with students and teachers. The structure of PDTs provided them with the kind of environment to do just that. They worked through problems - finding out what they knew or did not know. They had to confront their own strengths and weaknesses in probability as learners before they could think about how to engage students in the same problems. Some of this reflection occurred as they worked through problems, but a great deal of reflection came about by in-class discussions with peers.

The influence of the PDTs on coaches' perspectives and practices were examined by findings from their portfolio and questionnaire responses to answer the second and third research questions together.

Q2: How do the PDTs contribute to coaches' understanding of probability concepts?

Q3: How do the PDTs influence coaching roles?

Supporting mathematics teachers requires one know mathematics well enough to orchestrate learning activities in the classroom (Bengo, 2016; West \& Cameron, 2013). On one hand, providing coaches the opportunity to engage with problems that would be considered worthwhile tasks for students (Van de Walle, Karp, \& BayWilliams, 2013) afforded coaches to enhance their understanding of probability concepts taught at the gradelevels they support. Further, the coaches identified opportunities to closely observe students and reflect on student work, individually and collaboratively, as key contributors to improving their mathematical understanding.

Conversely, the open dialogue that occurred during the course related to the PDTs allowed coaches to dig deeply into what they knew as learners and what they needed to know as leaders. Coaches' reflections on these learning experiences will serve as examples for them to engage professionally with teachers about learning. The coaches in this program were encouraged to use approaches inspired by the PDTs with teachers they supported. We envision that the professional conversations that emerge from similar work with teachers will support 
teachers to understand the importance of engaging students in worthwhile mathematics and listening to students more closely in hopes of hearing their ways of understanding - not being too quick to discount students' work or explanation of work in favor of telling. As one coach wrote,

Through this class, I have begun to give more focus and attention to what the students know and understand versus what they are getting incorrect or what they don't know. I believe this is an important step for me because as we assess students and plan for instruction, we focus on where they are conceptually and develop instruction and tasks that will move them from where they are to where we want them to be.

This comment evidences an underlying purpose of the PDTs as a vehicle for developing a practice of learning. Developing a habit of learning is a leadership disposition recommended by the EMS standards (AMTE, 2013) and veteran coaching practitioners, West \& Cameron (2013), as essential for effective coaching.

\section{Promising Professional Development Task Structure}

As the researchers reflected on the intervention and findings of this study, a PDT framework emerged that depicted key features of the PDTs design (see Figure 4). The task framework is divided into three key areas coach (i.e., adults) problem solving, student work observation and analysis, and reflection (on the overall process and the generated artifacts). One very important aspect of this framework is that the problems used within must meet the characteristics of worthwhile tasks (e.g., Smith \& Stein, 2011; Van de Walle, Karp, \& Bay-Williams, 2013); otherwise, there would likely not be sufficient cognitive demand for the types of discussions and learning to manifest.

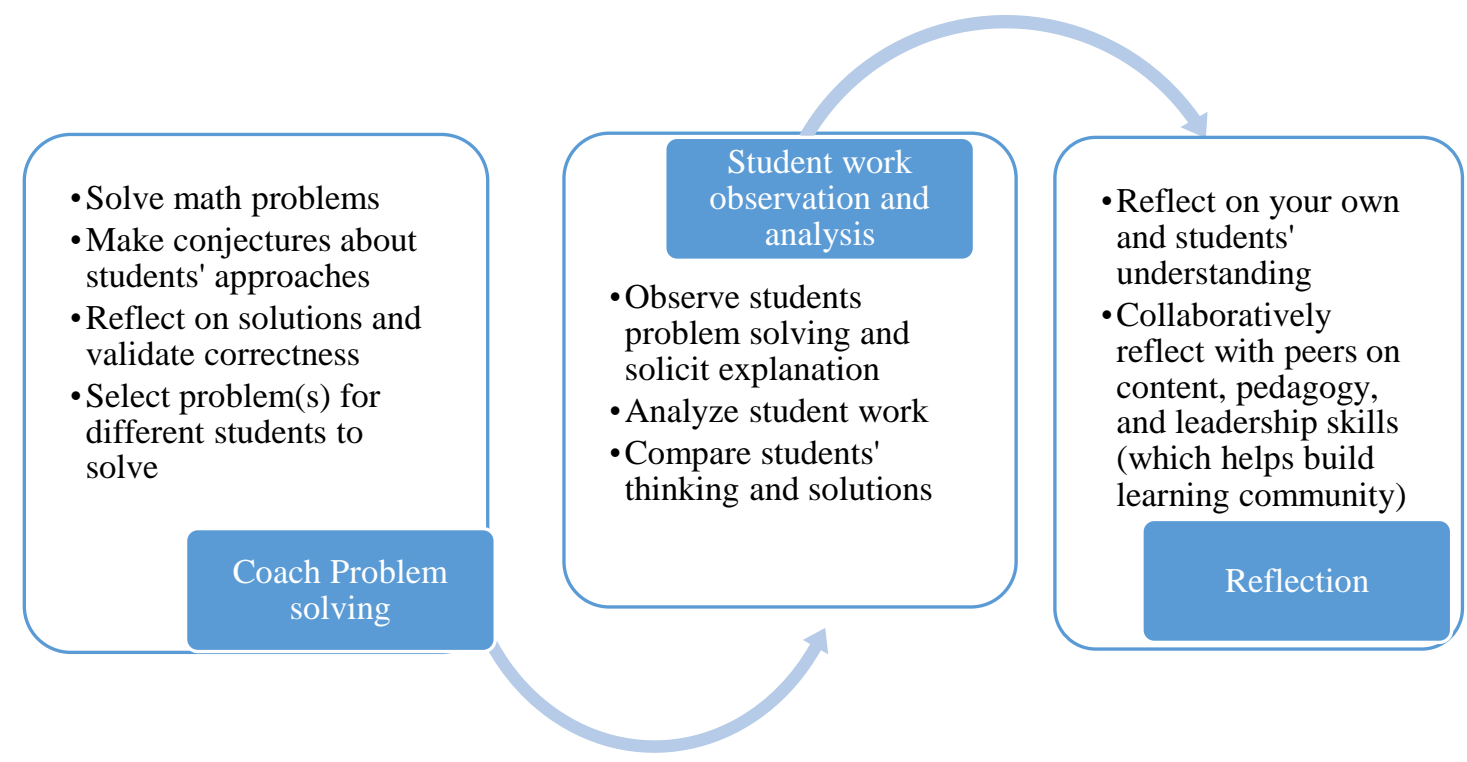

Figure 4. PDT structure: A task framework for adult mathematics learners

We assert that this proposed task framework for adult learners, as used in this study, was synthesized upon worthwhile tasks for coach development that led to professional learning for coaching and mathematical understanding of Grades 3-8 probability concepts. However, we posit that this framework should also be suitable with teachers, both pre- and in-service, and applicable to other strands of school mathematics.

\section{Recommendations for Future Study}

The results of this study provide a good basis for future study exploring ways to support coaches, teachers and students. We believe that the Task Framework for Adult Learners designed using teacher development principles established by Carpenter and Lehrer (1999) and informed by Polly, Mraz, and Algozzine's (2013) empirical synthesis of professional development literature should be considered for integration into future coaching and teacher education courses. One research area of particular importance is to conduct further study 
documenting the continuous changes of coaches' perspectives and knowledge during the implementation of PDTs. There is a need to collect additional data by interviewing coaches and providing them with quantitative measurements during different phases of the implementation of PDTs in order to understand and refine its structure.

This particular study was not focused on student achievement but rather what goes into supporting good coaching practices. The idea of using coaching as a way of providing professional development for teachers is not a new phenomenon, but one that supports teachers rather than coaches. More research is needed to help understand how greater support can be provided for mathematics coaches - a professional development for coaches. As was previously declared, coaches come from a variety of backgrounds - not always positions where mathematics content knowledge is at the forefront. Further research on tasks related to other content areas algebra, proportional reasoning, and geometry - are of interest to researchers. Adoption of the task framework for these content strands would provide needed evidence for how the professional community can support mathematics coaches in their work with students and teachers.

Lastly, providing coaches with the means to convince teachers that student work is valuable as an instructional tool is an area of interest and need. Students often know more than they are given credit for and coaches can help teachers recognize this point. Providing appropriate tasks that will interest and challenge students is key to hearing what they have to say about mathematics concepts. Developing a study around listening to student explanations would be of great value to coaches and teachers and would likely connect with other studies where student achievement has improved.

\section{Closing Thoughts}

As schools introduce and indoctrinate mathematics specialists and coaches into their classrooms, universities have an obligation to support these efforts by providing valuable education and professional learning opportunities. This research study presents one approach towards accomplishing this effort, but also presents new territory to further explore. By studying creative and sound methods of teaching mathematics to young learners, schools will possess mathematics experts who are not only strong in content and pedagogy, but also leaders to achieve greater success in mathematics teaching and learning. We hope to lead such efforts by adding to the literature in mathematics coaching while improving mathematics education for all.

\section{References}

Abdal-Haqq, I. (1995). Making time for teacher professional development (Digest 95-4). Washington, D.C.: ERIC Clearinghouse on Teaching and Teacher Education.

Ainley, J., Pratt, D., \& Hansen, A. (2006). Connecting engagement and focus in pedagogic task design. British Educational Research Journal, 32(1), 23.

Albert, J. H. (2003). College students' conceptions of probability. The American Statistician, 57(1), pp. 37 - 45.

Association of Mathematics Teacher Educators (2013). Standards for Elementary Mathematics Specialists: A Reference for Teacher Credentialing and Degree Programs. San Diego, CA: AMTE.

Ball, D. L., Hill, H. C., \& Bass, H. (2005). Knowing mathematics for teaching: Who knows mathematics well enough to teach third grade, and how can we decide? American Educator, 29(1), 14-17, 20-22, 43-46.

Bass, B. M. (1990). Bass \& Stogdill's Handbook of Leadership: Theory, Research, and Managerial Applications (3rd ed.). New York: The Free Press.

Batanero, C., \& Diaz, C. (2012). Training school teachers to teach probability: Reflections and challenges. Chilean Journal of Statistics, 3(1), 3-13.

Batanero, C., Godino, J. D. \& Roa, R. (2004). Training teachers to teach probability. Journal of Statistics Education, 12 (1). (www.amstat.org/publications/jse/v12n1/batanero.html)

Bengo, P. (2016). Secondary mathematics coaching: The components of effective mathematics coaching and implications. Teaching and Teacher Education, 60, 88-96.

Berry, R. Q., III, Bol, L., \& McKinney, S. E. (2009). Addressing the principles for school mathematics: A case study of elementary teachers' pedagogy and practices in an urban high-poverty school. International Electronic Journal of Mathematics Education, 4(1).

Biehler, R. (1990). Changing conceptions of statistics: A problem area for teacher education. Training Teachers to Teach Statistics: Proceedings of the International Statistical Institute Round Table Conference (pp. 2038). Voorburg, Germany: International Statistical Institute. 
Boaler, J. (2008). What's math got to do with it? Helping children learn to love their least favorite subject. New York: Penguin Group.

Brosnan, P., \& Erchick, D. B. (2010). Mathematics coaching and its impact on student achievement. Brief Research Report. In P. Brosnan, D. B. Erchick, and Flevares, L. (Eds.). Proceedings of the 32nd annual meeting of the North American Chapter of the International Group for the Psychology of Mathematics Education. Columbus, OH: The Ohio State University, 6, 1362-1370.

Campbell, P. F., \& Malkus, N. N. (2013). Elementary mathematics specialists influencing student achievement. Teaching Children Mathematics, 20(3), 198 - 205.

Campbell, P. F., \& Malkus, N. N. (2011). The impact of elementary mathematics coaches on student achievement. Elementary School Journal, 111(3), 430-454.

Campbell, P. F., \& Malkus, N. N. (2010). The impact of elementary mathematics specialists. The Journal of Mathematics and Science: Collaborative Explorations, 12, 1-28.

Canada, D. L. (2008). Conceptions of distribution held by middle school students and pre-service teachers. In Batanero, C., Burrill, G., Reading, C., Rossman, A., (eds.), Joint ICMI/IASE Study: Teaching Statistics in School Mathematics. Challenges for Teaching and Teacher Education. Proceedings of the ICMI Study 18 and 2008 IASE Round Table Conference. ICMI and IASE, Monterrey.

Carpenter, T. P., Fennema, E., Peterson, P.L., \& Carey, D. (1988). Teachers' pedagogical content knowledge of students' problem solving. Journal for Research in Mathematics Education, 19(5), 385-401.

Carpenter, T. P., \& Lehrer, R. (1999). Teaching and learning mathematics with understanding. In E. Fennema \& T. A. Romberg (Eds.), Mathematics classrooms that promote understanding (pp. 19-32). Mahwah, NJ: Lawrence Erlbaum Associates.

Chick, H. L., \& Pierce, R. U. (2008). Teaching statistics at the primary school level: beliefs, affordances, and pedagogical content knowledge. In Batanero, C., Burrill, G., Reading, C., Rossman, A., (eds.), Joint ICMI/IASE Study: Teaching Statistics in School Mathematics. Challenges for Teaching and Teacher Education. Proceedings of the ICMI Study 18 and 2008 IASE Round Table Conference. ICMI and IASE, Monterrey.

Chval, K. B., Arbaugh, F., Lannin, J. K., vanGarderen, D., Cummings, L., Estapa, A. T., \& Huey, M. E. (2010). The transition from experienced teacher to mathematics coach: Establishing a new identity. The Elementary School Journal, 111(1), 191-216. doi: 10.1086/653475.

Cobb, P., Gresalfi, M., \& Hodge, L. L. (2009). An interpretive scheme for analyzing the identities that students develop in mathematics classrooms. Journal for Research in Mathematics Education, 40(1), 40-68.

Common Core State Standards Initiative. (2010). Common Core State Standards for Mathematics. Washington, DC: National Governors Association Center for Best Practices and the Council of Chief State School Officers

Conference Board of the Mathematical Sciences (2012). The Mathematical Education of Teachers II. Providence RI and Washington DC: American Mathematical Society and Mathematical Association of America.

Desimone, L.M. (2009). Improving impact studies of teachers' professional development: Toward better conceptualizations and measures. Educational Researcher, 38 (3), 181-199.

Doerr, H. M. (2006). Examining the tasks of teaching when using students' mathematical thinking. Educational Studies in Mathematics, 62(1), 3.

Ellington, A., Whitenack, J., Trinter, C., \& Fennell, F. (2017). Preparing and implementing successful mathematics coaches and teacher leaders. The Journal of Mathematical Behavior, 46, 146-151.

Franklin, C., \& Mewborn, D. (2006). The statistical education of PreK-12 teachers: a shared responsibility. In Burrill, G. (ed.), NCTM 2006 Yearbook: Thinking and Reasoning with Data and Chance (pp. 335-344). Reston, VA: National Council of Teachers of Mathematics.

Fennell, F. S., Kobett, B. M., \& Wray, J. A. (2013). Elementary mathematics leaders. Teaching Children Mathematics, 20(3), 172-180.

Grant, A. M. (2012). An integrated model of goal-focused coaching: An evidence-based framework for teaching and practice. International Coaching Psychology Review, 7(2), 146-165.

Henningsen, M., \& Stein, M. K. (1997). Mathematical tasks and student cognition: Classroom-based factors that support and inhibit high-level mathematical thinking and reasoning. Journal for Research in Mathematics Education, 28(5), 524-549.

Hiebert, J., Carpenter, T. P., Fennema, E., Fuson, K. C., Wearne, D., Murray, H., \& Human, P. (1997). Making Sense: Teaching and Learning Mathematics with Understanding. Portsmouth, NH: Heinemann.

Hill, H. C., Ball, D. L., \& Schilling, S. G. (2008). Unpacking pedagogical content knowledge: Conceptualizing and measuring teachers' topic-specific knowledge of students. Journal for Research in Mathematics Education, 39(4), 372-400.

Hill, H. C., Schilling, S. G., \& Ball, D. L. (2004). Developing measures of teachers' mathematics knowledge for teaching. The Elementary School Journal, 105 (1), 11-30. 
Hodge, L. (2006). An orientation on the mathematics classroom that emphasizes power and identity: Reflecting on equity research. Urban Review, 38(5), 373-385.

Hufferd-Ackles, K., Fuson, K. C., \& Sherin, M. G. (2004). Describing levels and components of a math-talk learning community. Journal for Research in Mathematics Education, 35(2), 81-116.

Kraft, M. A., Blazar, D., Hogan, D. (2018). The effect of teacher coaching on instruction and achievement: A meta-analysis of the causal evidence. Review of Educational Research. Online publication of February 22, 2018, pp. 1-42. DOI: 10.3102/0034654318759268.

Lather, P. (1993). Fertile obsession: Validity after poststructuralism. Sociological Quarterly, 34(4), 673-693.

Martin, T. S. (Ed.). (2007). Mathematics teaching today: Improving practice, improving student learning. Reston, VA: National Council of Teachers of Mathematics.

MCP: Mathematics Coaching Program (2014). Retrieved from http://mcp-coaching.osu.edu/.

Merriam, S. B. (2009). Qualitative research: A guide to design and implementation. San Francisco, CA: John Wiley \& Sons, Inc.

Mudzimiri, R., Burroughs, E. A., Luebeck, J., Sutton, J., \& Yopp, D. (2014). A look inside mathematics coaching: Roles, content, and dynamics. Education Policy Analysis Archives, 22(53). http://dx.doi.org/10.14507/epaa.v22n53.2014. This article is part of EPAA/AAPE's Special Issue on Politics, Policies, and Practices of Coaching and Mentoring Programs, Guest Edited by Dr. Sarah Woulfin.

Nasir, N. S. (2002). Identity, goals, and learning: Mathematics in cultural practice. Mathematical Thinking \& Learning, 4(2/3), 213-247.

National Council of Teachers of Mathematics. (1991). Professional Standards for Teaching Mathematics. Reston, VA: Author.

National Council of Teachers of Mathematics. (2000). Principles and Standards for School Mathematics. Reston, VA: Author.

National Council of Teachers of Mathematics. (2014). Principles to actions: Ensuring mathematical success for all. Reston, VA: Author.

Peterson, P. L. (1988). Teachers' and students' cognitional knowledge for classroom teaching and learning. Educational Researcher, 17(5), 5-14.

Peterson, P.L., Fennema, E., Carpenter, T.P., \& Loef, M. (1989). Teachers' pedagogical content beliefs in mathematics. Cognition and Instruction, 6(1), 1-40.

Polly, D., Mraz, M., \& Algozzine, R. (2013). Implications for developing and researching elementary school mathematics coaches. School Science \& Mathematics, 113(6), 297-307. doi: 10.1111/ssm.12029

Putnam, R.T., \& Borko, H. (1997). Teacher learning: Implications of the new view of cognition. In B. J. Biddle, T. L. Good, \& I. F. Goodson (Eds.), The international handbook of teachers and teaching. Dordrecht, Netherlands: Kluwer.

Schoenfeld, A. H. (2005). Design experiments. In P. B. Elmore, G. Camilli, \& J. Green (Eds.), Complementary Methods for Research in Education (pp. 175-187). Washington, DC: American Educational Research Association.

Shaughnessy, J. M. (1992). Research in probability and statistics: Reflections and directions. In D. A. Grouws (Ed.), Handbook of Research on Mathematics Teaching and Learning (pp. 465-494). Reston, VA: National Council of Teachers of Mathematics.

Shulman, L.S. (1986). Those who understand: Knowledge growth in teaching. Educational Researcher, 15 (2), 4-14.

Shulman, L.S. (1987). Knowledge and teaching: Foundations of the new reform. Harvard Educational Review, $57(1), 1-22$.

Silver, E. A., Clark, L. M., Ghousseini, H. N., Charalambous, C. Y., \& Sealy, J. T. (2007). Where is the mathematics? Examining teachers' mathematical learning opportunities in practice-based professional learning tasks. Journal of Mathematics Teacher Education, 10(4-6), 261-277.

Silverman, J., \& Thompson, P. W. (2008). Toward a framework for the development of mathematical knowledge for teaching. Journal of Mathematics Teacher Education, 11(6), 499-511.

Skemp, R. R. (1976/2006). Relational understanding and instrumental understanding. Mathematics Teaching in the Middle School, 12(2), 88-95.

Smith, M. S., \& Stein, M. K. (2011). 5 Practices for Orchestrating Productive Mathematics Discussions. Reston, VA: National Council of Teachers of Mathematics

Stark, S., \& Torrance, H. (2005). Case study. In B. Somekh \& C. Lewin (Eds.), Research Methods in the Social Sciences (pp. 33-40). London: Sage.

Stein, M. K., Smith, M. S., Henningsen, M. A., \& Silver, E. A. (2000). Impementing Standards-Based Mathematics Instruction: A Casebook for Professional Development. New York: Teachers College Press.

Steinbring, H. (1990). The nature of stochastic knowledge and the traditional mathematics curriculum: Some experience with in-service training and developing materials. Training Teachers to Teach Statistics: 
Proceedings of the International Statistical Institute Round Table Conference (pp. 2-19). Voorburg, Germany: International Statistical Institute.

Stohl, H. (2005). Probability in teacher education and development. In Jones, G., (ed.), Exploring Probability in Schools: Challenges for Teaching and Learning (pp. 345-366). New York: Springer.

Sutton, J. T., Burroughs, E. A., \& Yopp, D. A. (2011). Coaching knowledge: Domains and definitions. NCSM Journal, 12(2), 15-23.

Tversky, A. \& Kahneman, D. (1974). Judgment under uncertainty: Heuristics and biases. Science, 185(4157), 1124-1131.

Van de Walle, J., Karp, K. S., \& Bay-Williams, J. M. (2013). Elementary and Middle School Mathematics: Teaching Developmentally (The Professional Development Edition for Mathematics Coaches and Other Teacher Leaders ed.). Upper Saddle River, New Jersey: Pearson Education, Inc.

West, L., \& Cameron, A. (2013). Agents of Change: How Content Coaching Transforms Teaching \& Learning. Portsmouth, NH: Heinemann.

Whitenack, J., \& Ellington, A. (2013). Supporting middle school mathematics specialists' work: A case for learning and changing teachers' perspectives. The Mathematics Enthusiast, 10 (3), 647 - 678.

Whitenack, J., \& Ellington, A. (2009). K-5 mathematics specialists' teaching and learning about fractions. The Journal of Mathematics and Science: Collaborative Explorations, 11, 109-126.

Wilson, S.M., Shulman, L.S., \& Richert, A. (1987). 150 different ways of knowing: Representations of knowledge in teaching. In J. Calderhead (Ed.), Exploring teachers' thinking (pp. 104-124). Sussex: Holt, Rinehart \& Winston.

\section{Author Information}

\section{Mary C. Enderson}

Old Dominion University

Department of Teaching \& Learning

Norfolk, VA 23529

USA

Contact e-mail: menderso@odu.edu

\section{Yating Liu}

Art of Problem Solving

10865 Rancho Bernardo Rd.

San Diego, CA 92127

USA

\section{Melva R. Gran}

Old Dominion University

Department of Teaching \& Learning

Norfolk, VA 23529

USA 